UDC 316.334 .56

LBC 60.56

\title{
CONTRADICTIONS IN THE CONSERVATION AND DEVELOPMENT OF THE SOCIAL RESOURCES OF THE VILLAGE
}

\author{
Peter P. Velikiy \\ Institute of Agrarian Problems of the Russian Academy of Sciences, Saratov, Russian Federation
}

\begin{abstract}
When the quantity and quality of material and social resources are discussed, the question always arises, why are such proportions formed, and not others? Prolonged inattention to the central problems of the village leads to the fact that it is experiencing a crisis of creation. The article analyzes the dominant meanings of the purpose of the agrarian system of society, which determine the priorities of its development, from the position of the social philosophy of understanding contradictions and on the facts of self-movement of the Russian village and agricultural production. The agrosphere contains deep contradictions, primarily in the state of social resources the intellectual, spiritual, moral, and professional potential of the village, contrary to the victorious realities about the success of the agro-industrial complex. The institutionalization and practices of including the population in independent management over the past decades have resulted in a fragmented system, in which the leading place is occupied by large structures that perform not only positive, but also destructive creation in the country. The author gives two examples of the way of life of a peasant family with a time lag of 150 years and reflects on the problems of labor overload of agricultural workers. The article reveals the specifics of the main contradictions in understanding the current situation, highlights the elements of each side that have the potential for assimilation. The author states the existence of contradictions between the dominance of large organizations of the divisional type within the fragmented economic structure of the village and the limited living space of peasant society. The author draws attention to the phenomenon of communication, constructed by such elements as communication, information and understanding. The article emphasizes the need to understand the situation of rural areas and the agricultural sector from the point of view of their own capabilities.
\end{abstract}

Key words: economic structure, village, living space, social resources of the village, dialectics, contradictions.

УДК 316.334 .56

ББК 60.56

\section{ПРОТИВОРЕЧИЯ В СОХРАНЕНИИ И РАЗВИТИИ СОЦИАЛЬНЫХ РЕСУРСОВ ДЕРЕВНИ}

\author{
Петр Панфилович Великий \\ Институт аграрных проблем РАН, г. Саратов, Российская Федерация
}

\begin{abstract}
Аннотация. Когда обсуждаются количество и качество материальных и социальных ресурсов, то всегда возникает вопрос, почему складываются именно такие пропорции, а не иные? Затянувшееся невнимание к центральным проблемам деревни ведет к тому, что она испытывает кризис созидания. В статье с позиции социальной философии понимания противоречий и на фактах самодвижения российской деревни и аграрного производства анализируются доминирующие смыслы предназначения аграрной системы общества, которые обусловливают приоритеты ее развития. Вопреки победным реалиям об успехах АПК агросфера содержит глубинные противоречия, прежде всего в состоянии социальных ресурсов - интеллектуальном, духовно-нравственном, профессиональном потенциале деревни. Институциализация и практики включения населения в самостоятельное хозяйствование за последние десятилетия вылились в раздробленную систему, в которой ведущее место занимают крупные структуры, выполняющие не только позитивное, но и разрушительное созидание в жизненном пространстве села.

Автор приводит два примера образа жизни крестьянской семьи с временным лагом в 150 лет и размышляет о проблемах трудовых перегрузок работников сельского хозяйства. В статье раскрывается специ-
\end{abstract}


фика основных противоречий в осмыслении сложившегося положения, выделяются элементы каждой стороны, обладающие потенциалом ассимиляции. Автор констатирует наличие противоречий между доминированием крупных организаций дивизионного типа внутри раздробленной хозяйственной структуры села и ограниченным жизненным пространством крестьянского социума. Описывается необходимость целеполагания в различных областях экономики, продовольственной безопасности страны, благополучия сельского населения. Обращается внимание на феномен коммуникации, сконструированной такими элементами, как сообщение, информация и понимание. Подчеркивается необходимость понимания положения деревни и аграрного сектора с точки зрения собственных возможностей.

Ключевые слова: хозяйственная структура, деревня, жизненное пространство, социальные ресурсы деревни, диалектика, противоречия.

Социальные ресурсы, понимаемые как качества людей, сформированные в процессе социализации вместе с условиями реализации, являются решающим фактором прогрессивного развития всех сфер и отраслей национального производства. Они участвуют в этом двояким образом: во-первых, влияют на культуру труда за счет уровня профессионализма, прилежания, ответственности, но результаты зависят и от условий реализации этих качеств. Одна ситуация, когда сельский механизатор работает на новой технике с электронными приборами, которыми она оснащена, другая, если трактор или комбайн давно технологически устарели. Не меньшее значение имеет его отношение к собственности, условия вознаграждения за труд, духовная атмосфера в социохозяйственной общности.

За развитие сельскохозяйственного производства отвечает множество ведомств, министерств, союзов товаропроизводителей, центральная и местная муниципальная власть, которые в последнее десятилетие пребывают в эйфории по поводу небывалых успехов АПК по экспорту зерна и по вкладу в ВВП. Одновременно с восхищением трудовой доблестью аграриев в публичном дискурсе отмечается, что проведена неудачная оптимизация социальной инфраструктуры, ухудшившая условия медицинской помощи, получения образования, почти полностью приостановилась создание рабочих мест и др.

В связи с этим обратимся к проблеме диалектики противоречий в общем плане и применении ее к сельским реалиям. Когда речь заходит о количестве и качестве материальных и социальных ресурсов, всегда возникает вопрос, почему складываются именно такие, а не иные пропорции. Как отмечали экономисты-аграрии, на $27 \%$ сельского населения в общем бюджете страны приходится только 1,5 \% средств, в то же время до 1 трлн руб. изымается из сельскохозяйственной отрасли через разорительные для крестьянства фискальные акции перекачки или пресловутого «перераспределения» [Буздалов 2009].

Хотя в последние годы АПК страны получил значительные финансовые вливания, но практики перераспределения средств, о которых писали экономисты 10 лет тому назад, сохранились. По данным исследований Центра продовольственной политики РАНХиГС, $0,1 \%$ сельскохозяйственных объединений имеет в собственности 2,4 млн га сельскохозяйственных угодий $(13,6 \%)$, а у 12,2 тыс. $(62,3 \%)$ сельскохозяйственных организаций, из списка учтенных, в собственности земли нет. Первые в 2016 году получили 57,9 \% всех выданных кредитов, вторые - 12,4 \% [Шагайда, Узун web]. Первая группа - это процветающие по прибылям агрохолдинги, вторая обычные сельскохозяйственные организации различных укладов (АО, товарищества, СПК), у которых дела идут хуже: за 2010-2015 гг. у них стало меньше тракторов, косилок и других установок на 16-20\%, сеялок и плугов на 25 \% [Кулов, Соловьева 2017, 74].

На разных полюсах находится и хозяйственно-экономическая организация: агрохолдинги и крупные самостоятельные сельскохозяйственные предприятия имеют инфраструктуру переработки и получают доход от продажи готового к потреблению продукта, между тем как мелкие производители поставляют на рынок в основном сырье. Отличаются и условия труда, более жесткие по контролю за точностью технологий в крупных и менее - в средних и мелких организациях. Это относится и к годовой нагрузке, что в совокупности приводит к дифференциации работ- 
ников. По утверждению наемных работников, в первом случае человеку старше 40 лет предъявляются такие требования, что трудно выдержать нагрузку. Поэтому и менеджмент таких организаций предпочитает набирать более молодые кадры, между тем как во второй группе хозяйств работники предпенсионного и пенсионного возраста занимают доминирующее место.

Еще одна укоренившаяся на много лет проблема - низкая оплата труда: приняв среднюю зарплату в стране за 100, получим в обрабатывающих отраслях 97, в добыче полезных ископаемых 209, в сфере финансов 257, а у работников сельского хозяйства - 47 [Григорьев, Плаксин, Салихов 2008, 31]. Если учесть, что менее половины трудоспособных сельских жителей имеют рабочие места в формализованной структуре сельского хозяйства, 13,6 \% работают без трудового соглашения, $10,6 \%$ временно являются безработными, то их доходы будут отставать даже от той минимальной зарплаты, которая установлена МРОТ [Тощенко (ред.) 2016, 311].

Таким образом, в экономике и структуре аграрных предприятий страны сложилась раздробленная структура, состоящая из крупных и мелких хозяйствующих субъектов, которые находятся в неравных условиях функционирования жизнедеятельности сельских жителей как участников этих коллективных акторов.

Разнообразие хозяйствующих субъектов, сосуществование крупхозов и фермеров, индивидуальных предпринимателей и владельцев семейных подворий считается достижением аграрной реформы, поскольку открыло простор для реализации творческого потенциала людей. Однако, когда внутри структуры одни субъекты относительно легко преодолевают вызовы и риски и процветают экономически, а другие находятся на уровне выживания, и сходят с арены хозяйствования и вообще из сельского жизненного пространства, то по-видимому, не все благополучно в этом процессе. В этой связи нужно оценить смыслы, которые разделяют разные субъекты, живущие в селе или вне его, но влияющие на решение актуальных вопросов жизнеустройства, экономики труда и другие аспекты. До начала аграрной реформы 1990 г. трудовая занятость была полной (исключая женщин с детьми младшего возраста, которые, тем не менее, выполняли подсобные работы в дни «страды»). Ценность рабочего места была неукоснительной и не вызывала сомнения надежности.

По данным сравнительного исследования начала 1970 и конца 1990 гг., проведенных в трех регионах (Краснодарском крае, Саратовской и Тверской областях, где опрошено 1000 и 500 человек в 70 селах) [Арутюнян (науч. ред.) 1995, 47], сельское население в 1970-х гг., то есть на начальном этапе аграрной реформы, не испытывало таких издержек, как на завершающем этапе и в наши дни.

Большинство опрошенных отметили более предпочтительной форму хозяйствования в государственной и колхозной структурах: от 53 до $70 \%$ - работники квалифицированного труда и 46-60 \% - труда высокой квалификации, были за сохранение землепользования вне частной формы и только 10-20 \% поддерживали идею купли-продажи и 3-10\% желали ее приобрести.

Социальный опыт крестьянства просто не мог быть другим, исходя из ситуации постоянного воздействия (включая и принуждение власти), к выполнению трудового долга. Заработками были удовлетворены $47 \%$ квалифицированных работников физического труда и специалисты - технологи высшей квалификации. В 1991-1992 гг. эти показатели резко упали - до $13 \%$ у первой и от 8 до $28 \%$ у второй группы.

Эти положения имеют существенное смысловое значение для понимания положения (бытия) отдельных подсистем общества, в нашем случае аграрной его подсистемы.

Если мы обратимся к положению сельского социума, начиная с середины XIX в. и по настоящее время, то обнаружится бесспорный факт о неизменно низком уровне благосостояния подавляющей его части - крестьянства. При этом нельзя считать, будто государство и общество не беспокоились об этом. Ведь были аграрная реформа 1861 г., Столыпинский проект, коллективизация, индустриализация сельского хозяйства и создание социальной инфраструктуры. Аграрная реформа 1990 г. также предполагала дать простор для реализации потенциала хозяина земли посредством доступа к владению сельскохозяй- 
ственными угодьями и самостоятельному хозяйствованию - все эти действия, помимо целей сугубо политических и экономических, содержали и благие намерения - сделать жизнь сельских жителей более благополучной.

Вместе с тем, существует парадоксальность длящаяся, мало изменяющаяся во времени, которую обусловливает диктат живой материи; и чем меньше хозяйствующая общность, тем она жестче. И это почти неизменно, несмотря на совершенствование технических средств. Из книги А. Васильчикова, выпущенной в 1881 г., известно, что житель Тверской, Новогородской, Псковской губернии (не говоря о крайнем севере) прикован на все лето к полевым работам на своей земле, работы эти следуют одна за другой без перерыва, с ранней весны до осенних заморозков: начиная посев с ранних яровых (гороха, овса) в конце апреля, оканчивает... не ранее половины мая; затем приступает к вывозке и запахиванию навоза; с Иванова или Петрова дней (конец июля) принимается за сенокос... по окончании надо двоить пар, жать рожь, потом сеять озимый хлеб и убирать яровой, что продолжается до конца августа или начала сентября. Если посеян лен, то мочка и сушка его продолжаются до конца сентября, вплоть до заморозков и распутицы [Князь Васильчиков 1881, 91].

Прошло 150 лет с момента наблюдения жизни крестьянской семьи, но диктат хозяйства, даже при сокращении числа отраслей в нем, остается. Яркий факт, подтверждающий эту мысль - самостоятельное хозяйствование современной семьи. Поскольку заработок в современных сельскохозяйственных организациях небольшой, и сельская семья не может накопить средств на самые актуальные нужды, жители обращаются к ресурсам подворья. Некоторые вообще ограничивают свою трудовую занятость исключительно семейным хозяйством.

По нашим данным, около $10 \%$ семей довели его до уровня товарности, позволяющей жить более обеспеченно, чем те, кто ограничивается работой в сельскохозяйственной организации или совмещая ее с небольшим ЛПХ.

Кейс «Хозяйственная самодеятельность современной сельской семьи» 2019 г. Муж 38 лет, жена 35 лет, две дочери 15 и 6 лет. Хо- зяйство: кролики - 70, куры - 150. Продукция в объеме 90-85 \% идет на продажу. Техническое оснащение: легковой автомобиль с прицепом, мотоблок с разными наладками, измельчитель зерна. В доме набор бытовых приборов, новая мебель, компьютер с выходом в Интернет.

Повседневность семьи жестко привязана к обслуживанию животных. Муж ежедневно с 7 ч. 30 мин. до 10 ч. вечера (с несколькими перерывами на завтрак, обед, часовой отдых, ужин) выполняет предопределенные трудовые операции, которые нельзя ни отложить, ни отменить. В субботу и воскресенье - поездка до торговых точек (70 км в одну сторону), которые официально не оформлены, и присутствует чувство опасения попасть под санкции.

Жена работает наравне с мужем: в 6 ч. 30 мин. готовит завтрак, далее проводит уборку на подворье, кормление животных. Рабочий день в июле-августе у обоих супругов длится 14-16 часов. Дочь - школьница: в выходные дни, свободные от учебы, в течение 2-3 часов помогает матери в обустройстве быта. Такой режим повседневности не нарушается ни праздниками, ни необходимостью отлучиться из дома в целях гостевания, посещение лечебных и культурно-развлекательных учреждений. При таком напряженном ритме, семья сохраняет оптимизм. Оба супруга по 10-балльной шкале определили удовлетворенность жизнью в высшем значении.

Итак, перед нами два образа крестьянской семьи с временным лагом в 150 лет, в повседневности которых много общего. Современная семья, несмотря на несравнимо более развитую инфраструктуру хозяйства, все-таки подчинена законам поддержания жизни живой матери. Это относится к тем, кто предпочитает и полеводство, и животноводство, причем последнее связывает свободу в наибольшей мере.

Проблема трудовых перегрузок работников сельского хозяйства была актуальной пока ученые осмысливали преодоления различий, «подтягивания» деревни до уровня города [Заславская, Рывкина (ред.) 1980]. К сожалению, в новое время эта тематика по существу исчезла, хотя проблемы доведения индивида до пределов его физических возмож- 
ностей, рационализации во имя монетарных целей или простого выживания, актуальны для акторов всех отраслей хозяйства и сфер общества.

Таким образом, состояние многих процессов в деревне, сельских территориях, в аграрном секторе экономики сохраняет и воспроизводит множество пртиворечий. В итоге предпосылок, созданных институализацией направлений аграрной реформы, сложились многочисленные противоречия в способах вхождения села в рыночный монетарный порядок его существования. Оно приняло все особенности рыночной экономики, структурных и социально-культурных отношений. В экономике стали побеждать сильнейшие. Хотя и была сделана попытка адекватного ответа большинству постколхозников - создать производственные кооперативы, которые сохраняют коммунарные характеристики труда и внутриколлективных отношений, но их расцвету воспрепятствовали, во-первых, институализация создания фондов недвижимости. Бедному сельскому населению предлагалось в качестве условия членства внести от себя средства. Во-вторых, сформированный уклад, поставленный в рамки рыночной экономики по-российски, был подавлен и перешел в руки акционерных обществ.

Все эти несообразности можно объяснять с «материальных» позиций, принимая посылку, что в некий конкретный момент времени решалась другая проблема и на нее (а не на деревню) обращалось особое внимание, проектирование и финансирование. Но затянувшееся невнимание к центральным проблемам деревни ведет к тому, что она испытывает кризис созидания.

Социально-экономическая и духовная ситуация второй половины XX и начала XXI в. в России детерминирована глобальными и локальными воздействиями материального, организационного и политического характера. Их невозможно рассматривать в одной статье. Мы ограничим свою задачу анализом смысловой стороны функционирования аграрного сектора и существования российской деревни.

По удачному выражению Г.В. Плеханова, между сознанием и поведением лежит бездна смысла. Нет ни одного исторического факта, которому не предшествовало бы, ко- торое не сопровождало бы и за которым не следовало бы известное состояние сознания [Плеханов 1956, 237]. Наиболее значимым атрибутом смысла является совокупность его целей-принципов, выступающих своеобразным компасом ориентации действий в общественной и личной жизни индивида. Понимание человеком своей роли и социохозяйственной структуры, в которую он входит, является стержнем сознания и поведения.

Модель социальной истины должна быть сконструирована таким образом, чтобы учесть специфику социальной реальности, выступающей одновременно и как бытие, и как смысл [Коршунов, Мантатов 1988, 93]. И в том случае, когда предметное содержание отвергаемого или, наоборот, «внедряемого» не обладает объективностью, оно с трудом реализуется в реальной жизни. Смысл является единством материального и духовного, практик деятельности и смыслов. Мысль Маркса об отличии архитектора, который первоначально осмысливает проект, а затем действует, от пчелы, не обладающей этой способностью, можно считать удачной метафорой оценки, преобразующей роли осмысления жизненной реальности. По Гегелю действительность есть единство бытия и понятия, и по его логике, чтобы понять самодвижение мира, необходимо выделение основных противоречий и его полярных сторон, что полностью можно отнести и на диалектику в отдельных подсистемах общества. Исторически сосуществуют два противостоящих смысловых полюса деревни и их субъектов (носителей). На одной стороне само крестьянство, жители села, которые от поколения к поколению заставали ситуацию обделенности социальными благами и отсутствия перспектив наступления благоприятных перемен. На другой - господствующее в обществе «агентство», состоящее из влиятельных акторов власти, политики, экономики, духовного производства, которое создает и реализует концепции «предназначения крестьянства».

Так было в российской империи, в советское и настоящее постсоветское время. Почему почти два века не меняется существенно данная ситуация? Версий объяснения этого много, и они многообразны - от исторических, географических, экономических и поли- 
тических до ментальных обусловленностей, которые нужно учитывать. Однако действует еще стратегия сил, условно «ответственных» за разные стороны жизни села и хозяйствования его обитателей. Это бюрократия властных структур, партии и общественные объединения, которые работают по реализации целей власти и предназначения деревни. Убогая бытовая обустроенность сельской семьи, и в тоже время способность крестьянства поставлять хороших солдат для армии, достаток продуктов питания в городах и другие факты формировали смыслы данной стороны взаимодействия, что это и есть норма, которая идеологически вносилась в сознание сельского социума. Им, крестьянам, колхозникам, фермерам, достаточно и того, что они имеют, вот суть смысловых установок этой стороны.

В постсоветский период либеральная модель реформирования сохранила традиционное наделение сельского социума заниженными потребностями и стандартами жизненных условий. Одновременно добавилось новое: романтическая оценка ожидаемого поведения крестьян, получивших свободу от ограничений колхозного порядка, которая будто бы подвинет их к поведению (в отношении частной земли и способов хозяйствования), схожему с поколениями, жившими на простоpax России сто лет тому назад. Хотя из десятка миллионов колхозников трудоспособного возраста нашлось немало романтиков и расчетливых людей, которые последовали сигналам новой идеологии, но в целом крестьянская рациональность, вкупе с осторожностью, оказались доминирующими. Фермеров в стране немного, большинство же стали наемными работниками, сдали принадлежащие им земельные паи хозяевам новых укладов и получают за это весьма скромную оплату, чаще всего зерном и другими продуктами, которых часто не хватает для содержания неизбывной формы выживания - семейного подворья, ЛПХ.

О необходимости взвешенной оценки схожего в общественных явлениях прошлого в новой исторической ситуации С.Э. Крапивенский предупреждал как раз в первые годы аграрной реформы. Он полагал, что у сравниваемых явлений надо учитывать наличие, прежде всего, социально-экономической и тех- нико-технологической почвы, а если речь идет о разных формациях или разных ступенях цивилизации, их принадлежность к однопорядковым эпохам (скажем, к эпохе становления новой формации) [Крапивенский 1996, 342].

Недомыслие по поводу врастания новых хозяйственных отношений в жизнь сельского населения проявилось и в неотработанности необходимых институциональных норм, несоизмерения достатка финансовых возможностей семей и величины всякого рода оплат за доступ вхождения в фермерский уклад, малый бизнес, индивидуальное предпринимательство, неадекватные налоги и штрафы фискальных органов. Постколхозное крестьянство в своем большинстве сохранило верность и доверие традиционному способу выживания за счет собственного труда на земельных угодьях.

В этой связи следует обратить внимание на феномен коммуникации, сконструированной такими элементами, как сообщение, информация и понимание, нагружая каждый из них неравновесными значениями. Какой бы смысл не вкладывался в сообщение, принимающая инстанция выделяет из него информацию по своему усмотрению, с позиции того, зачем это говорится, насколько в сообщении скрыты реальные или мнимые проблемы.

В одних случаях на это влияет полнота сообщений, в других подход к извлечению информации, в-третьих - избрание концептов осмысления с разных позиций: рациональности, норм морали и права, или политических приоритетов. Эти положения ярко проявились в практиках постсоветского функционирования российского АПК, который проходил стадию подготовки к вступлению в ВТО. Производственники с мест и аграрная наука заполнили медийное пространство сведениями о неизбежности провалов в отечественном сельском хозяйстве в связи с членством в ВТО. Госслужащие, готовящие проекты вступления в ВТО, не находили в них «достойной» информации для адекватного понимания последствий.

Обращение к смыслам с позиции упреждающий роли их в формировании социальных процессов, которые могут приобретать разное содержание и направленность, проявилось и в философии аграрной реформы. У либерально 
мыслящих младореформаторов не существовало иной модели, кроме распространения фермерства, опыт которого в России был, но в исторически далекий период.

Вопрос о том, что из этого получилось в реальности, не имеет единой оценки. Для сторонников, связывающих жизнь сельского населения преимущественно с улучшением условий быта, там все нормально. Носители идей противоположной стороны считают, что приспособление к явным издержкам села имеет пределы. Первые консервируют многие процессы в деревне и АПК, и по существу призывают сельское население к жизни в условиях все больших ограничений (хотя их нельзя выдерживать беспредельно). Пример тому - трудовые отходники, которые, старея, уже не могут выживать в условиях ритма трудовой нагрузки, задаваемого работодателем энергетических предприятий, бесконечными миграциями, оторванностью от семей.

Основными понятиями, которые разделяют противоположные стороны, является целеполагание в различных областях экономики, удобство управления экономическими процессами, продовольственная безопасность страны, благополучие сельского населения. Их смысловое наполнение дополняется оценками объективных сторон реализации: территориального пространства, предшествующего уровня развитости, демографической и профессиональной структуры. Но на смыслах целей и оценки объективных и субъективных предпосылок лежит груз влияния сиюминутных ситуаций. Например, опасение несбалансированности бюджета государства смещает смысловые акценты на предпочтение крупных хозяйственных структур, которые эффективны в одном отношении и, одновременно, их деятельность приносит издержки. Смыслы другой стороны, массовых слоев сельских жителей, выстраиваются в другой иерархии, замыкаясь на возможность создания ресурсов за счет собственного труда. Но для этого нужны: доступное пространство (пахотная земля, лес, водоемы), чтобы обрабатывая его соответственно специфике природного объекта получать продукт. Нужны доступные и в нужном ассортименте орудия труда, а самим работающим индивидам - квалификационные компетенции. К сожалению, реализовать социальный потенциал в полной мере современному сельскому населению не получается. Репродукционные круги в демографическом, профессиональном и ценностном состоянии сельского социума по многим параметрам демонстрируют возврат к исходному уровню, то есть воспроизводство происходит без восхождения на новый, более совершенный уровень.

Полярность сторон, поддерживаемая смыслами концептуального уровня, в жизни порождает множество проблем. Одну сторону противоречия образует «организация проиесса», которую олицетворяет дивизионный организм - агрохолдинг, другую - статичная, где господствует слитность трудового процесса и расселения. Первая приходит в сельское пространство со всем своим: техникой, работниками, бытовой инфраструктурой, приспособленных для того, чтобы извлечь из земельных площадей свою выгоду. Никакого общения с местным населением, как правило, им не нужно. Местное население характеризует эту ситуацию в следующем нарративе. «Поля, на которых работали жители нашего села до реформы, теперь стали нам недоступныl. Весной привезли откуда-то (?!) трактора - вспахали. Летом никого не было. Пришла осень - опять привезли комбайны. Скосили, зерно куда-то увезли. К нам в село даже воды попить никто не зашел» (мужчина, житель села).

Дивизионная структура (не обязательно агрохолдинг, это может быть горнодобывающее или энергетическое предприятие) все эти важные моменты для жизни местного населения в полной мере учесть не может. Ее функция - разрушающее созидание (И. Шумпетер).

Поскольку доминирование крупных организаций и раздробленность структуры сельского хозяйства, несомненно, сохранятся и в обозримом будущем, и она во многом будет определять структуру сельских поселений, то смысловая перспектива их равноправия становится актуальной задачей философии и социологии.

Положение диалектики о том, что каждая сторона переходит в другую, И.А. Ильин показал на следующей схеме. Возможна такая ситуация, когда свое существование обе стороны А и В оправдывают по принципу «Враг утверждает себя в своем собственном 
враге», но в итоге превращает себя в своего собственного врага, что непродуктивно. И жизнь подталкивает к тому, что каждая сторона творчески начинает принимать в себя содержание другой стороны.

И если в первом случае A $\longrightarrow$ В как бы непримиримо противоположны, неподвластны и лишены гибкости, то далее в каждой стороне происходят некие изменения, и она излучает их на сторону, полярную ей.

Теперь через моменты, или корреляты, стороны А и В превращаются в $\mathrm{A}_{1} \longrightarrow \mathrm{B}_{1}$. То есть из двух противоположных сторон А и В каждая получила двойное бытие: во-первых, она есть «в себе», во-вторых, она есть «в другой». Новое содержание каждой стороны обогащено творческим внедрением чужого содержания, обладающим потенциалом ассимиляции [Ильин 2002, 199].

Данную абстрактную схему разрешения противоречий можно применить и к смыслам сельского бытия. Одна сторона: доминирование крупной организации дивизионного типа внутри раздробленной хозяйственной структуры; другая - ограниченное жизненное пространство крестьянского социума. Если дивизионная организация может существовать до полной выработки искомого ресурса, почти не соприкасаясь с жителями локальных общностей, то репродуктивные способности села при такой расстановке сил по всем сферам и отраслям ослабевают и исчезают совсем. Однако предпосылки сближения все же имеются: агрохолдинг вынужден корректировать смыслы тех, кто укорененно живет в сельских территориях. Влияют следующие моменты:

- потребность в трудовых ресурсах, которые воспроизводятся в локальных сообществах и предрасположенность нести расходы на их обучение, обустройство жизненной среды отдельных поселений;

- рост агрокультуры из опасения конкурентов, претендующих на площади возделываемой земли, которые могут воспользоваться несостоятельностью поведения организаций агрохолдинга в социальной среде региона;

- адекватный ответ на давление потребителя продукции, необходимость корректировки социального поведения и агрокультуры;
- подражание позитивным образцам взаимодействия с локальными сообществами; - адекватный ответ на давление сил демократии в обществе: партий, НКО, прогрессивных журналистов и ученых, ответственных за судьбу отечественной деревни.

Однако пробуждение и действие этих моментов внутри данной стороны противоречия, хотя и предопределено логикой диалектики, но может происходить в вялотекущем режиме. И тогда инициатором (модератором) ускорения могут стать властные структуры, внутри которых изменяются смыслы относительно состояния не только экономики, но и сохранения села и его жителей. Менеджмент агрохолдингов включен в коммуникационные процессы региона и не может не реагировать на настроение властной элиты регионов. Например, агрохолдинги в Белгородской области весьма эффективно, хотя и односторонне, отреагировали на нужды села, вложив большие средства в улучшение дорог, создание социокультурной инфраструктуры, обеспечение рабочими местами жителей. Не исключено, что этому способствовало «обнародование» смыслов губернатора Савченко, который заявил, что агрохолдинги уже отработали свое предназначение.

Сторона противоречия жизненное пространство села тоже содержит элементы, которые способны оживить сельскую реальность и стать коррелятом для изменений внутри другой стороны - дивизионных гигантских структур, ныне отстранившихся от общих проблем села. Нельзя не отметить еще один элемент данной стороны противоречия: сохранение качества этоса, способствующего поддержанию солидарности, уравновешивая модели бинарного взаимодействия (руководитель подчиненный, хозяин - наемный работник), что очень важно, поскольку дает в руки трудового коллектива возможность противостоять управленческому деспотизму.

На первоначальном этапе аграрной реформы были попытки распространить в территориях страны формы хозяйствования, аккумулирующие в себе коммунарные и приватные потенции (аналогично кибуцам и мошавам, поражающим мир своими хозяйственными успехами). Дело не пошло, потому что у новой муниципальной власти не нашлось сил 
помогать каждой организации в ее становлении. Вот почему и в данном случае нужен повторный смысловой вход в структуру хозяйствования.

Возможно, в смыслах современных управленцев возникнет опасение реанимации неких «родовых пятен» советских колхозов. Однако сегодня сельские общности по демографическому составу уже другие по сравнению с тем, чем они были в начале 90-х гг. $\mathrm{XX}$ века. Они уже приобщились к жесткой дисциплине труда в условиях рынка.

Таким образом, итоги разрешения противоречия между гигантоманией и одновременно раздробленностью в организации аграрной экономики и угнетенным социальным пространством территорий лежат в смыслах акторов коллективных и индивидуальных. Село, локальное сообщество являются слабым элементом полярной стороны. Поэтому только распространение смыслов с позиции сохранения кода народной культуры, территорий, резерва армии, то есть целеполагания в общенациональном масштабе может создать корреляты воздействия на противоположные стороны противоречия.

С позиции управления парадокс устоявшейся организации сельскохозяйственного производства в России заключается и в ослаблении возможностей маневрирования его ресурсами при изменении ситуаций в политике и в мировой экономике. Хотя, как утверждает эксглава Росстата, импортозамещение растет, особенно в сельском хозяйстве, но 48 \% продукции АПК производят агрохолдинги, семенной блок на 60-70 \% импортный, почти 60 \% рынка переработки молока, более 70 \% соков, почти 80 \% замороженных овощей и пива, 90 \% плодоовощной продукции - находятся под иностранной юрисдикцией [Чуйков web]. Добавим к этому тревожному предупреждению также риски закрытия границ государств, как это имело место при пандемии в 2020 году.

Стечение целого ряда обстоятельств в миросистеме, таких как уроки стихийного заполнения Европы мигрантами, локальные военные конфликты, идеи о необходимости поиска внутренних ресурсов развития страны, а также адекватная оценка издержек от наивного ожидания успехов от «невидимой руки» рынка, вызывают необходимость осмысления положения деревни и аграрного сектора с позиции собственных возможностей в настоящее время и применительно к будущему. Повторный вход в осмысление сельских проблем, трактующих ресурсы обновления через обращение к ретроспективным, инновационно-современным и перспективным аспектам, настоятельно необходим.

\section{СПИСОК ЛИТЕРАТУРЫ}

Арутюнян (науч. ред.) 1995 - Арутюнян Ю.В. (науч. ред.). Россияне: жители города и деревни. М.: Институт этнологии и антропологии PAH, 1995.

Буздалов 2009 - Буздалов И.Н. Российское крестьянство под прессом монопольного окружения и структурных переносов в экономике // Миссия российского крестьянства в формировании социального государства. Белгород: БелГСХА, 2009.

Григорьев, Плаксин, Салихов 2008 - Григорьев Л., Плаксин С., Салихов М. Посткризисная структура экономики и формирование коалиций для инноваций // Вопросы экономики. 2008. № 4. С. 25-43.

Заславская, Рывкина 1980 - Заславская Т.И., Рывкина P.B. (ред.). Методология и методика системного изучения советской деревни. Новосибирск: Наука, 1980.

Ильин 2002 - Ильин И.А. Собрание сочинений. Философия Гегеля как учение о конкретности Бога и человека. Т. 1. Учение о Боге. М.: Русская книга, 2002.

Князь Васильчиков 1881 - Князь Васильчиков $A$. Сельский бытъ и сельское хозяйство въ России. СПб.: Типографія М.М. Стасюлевича, 1881.

Коршунов, Мантатов 1988 - Кориунов А.М., Манmaтов B.В. Диалектика социального познания. М.: Политиздат, 1988.

Крапивенский 1996 - Крапивенский С.Э. Социальная философия. Волгоград: Комитет по печати, 1996.

Кулов, Соловьева 2017 - Кулов А.Р. Соловьева Н.Е. Состояние технической обеспеченности сельского хозяйства и тенденции развития на современном этапе // Научный результат. Экономические исследования. 2017. Т. 3, № 2. С. 72-81.

Плеханов 1956-Плеханов Г.В. Избранные философские произведения в 5 т. Т. 2. М.: Гос. изд-во полит. лит., 1956.

Тощенко (ред.) 2016 - Тощенко Ж. Т. (ред.). Смыслы сельской жизни (Опыт социологического ана- 
лиза). М.: Центр социального прогнозирования и маркетинга, 2016.

Чуйков web - Чуйков $A$. Съели Россию оффшорные волки. Интервью с д.э.н. В.М. Семчерой // yandex.ru/turbo/argumenti.ru/s/society/2020/ 02/650972

Шагайда, Узун web - Шагайда Н., Узун В. Как агрохолдинги меняют сельское хозяйства // https://www.vedomosti.ru/opinion/articles/ 2019/01/22/792164-agroholdingi-menyayut.

\section{REFERENCES}

Harutyunyan Yu.V. (ed.). 1995. Russians: residents of the city and village. Moscow, Institute of Ethnology and Anthropology RAS.

Buzdalov I.N., 2009. The Russian peasantry under the pressure of monopoly environment and structural transfers in the economy. The mission of the Russian peasantry in the formation of a social state. Belgorod, BelSAA.

Grigoryev L., Plaksin S., Salikhov M., 2008. Postcrisis structure of the economy and the formation of coalitions for innovation. Issues of Economics, no. 4.

Zaslavskaya T.I., Ryvkina R.V. (eds.), 1980. Methodology of a systematic study of the Soviet village. Novosibirsk, Nauka Publ.
Ilyin I.A., 2002. Collected works. Hegel's philosophy as a doctrine of the concreteness of God and man. Vo. 1. Teachings of God. Moscow, Russkaya Kniga Publ.

Knyaz Vasilchikov A., 1881. Rural life and agriculture in Russia. Saint Petersburg, 1881.

Korshunov A.M., Mantatov V.V., 1988. The dialectic of social cognition. Moscow, Politizdat.

Krapivensky S.E., 1996. Social Philosophy. Volgograd, Press Committee.

Kulov A.R. Solovieva N.E., 2017. State of technical security of agriculture and development trends at the present stage. Scientific Result. Economic research, vol. 3, no. 2.

Plekhanov G.V., 1956. Selected philosophical work in 5 volumes. Vol. 2. Moscow, State Publishing House of Polit. lit.

Toshchenko J.T. (ed.). 2016. The meanings of rural life: (The experience of sociological analysis). Moscow, Center for Social Forecasting and Marketing.

Chuykov A. Offshore wolves ate Russia. Interview with Doctor of Economics V.M. Semchera. Arguments of the week. February 19 $9^{\text {th }}$ URL: yandex.ru/ turbo/argumenti.ru/s/society/2020/02/650972.

Shagayda N., Uzun V. How does agricultural holdings change agriculture. URL: https:// www.vedomosti.ru/opinion/articles/2019/01/ 22/792164-agroholdingi-menyayut.

\section{Information About the Author}

Peter P. Velikiy, Doctor of Sciences (Philosophy), Professor, Leading Researcher, Laboratory of Social Development of the Agro-Industrial Complex and Rural Territories, Institute of Agrarian Problems of the Russian Academy of Sciences, Moskovskaya St, 94, 410012 Saratov, Russian Federation, iagpran@mail.ru, https://orcid.org/0000-0001-5104-2153

\section{Информация об авторе}

Петр Панфилович Великий, доктор философских наук, профессор, ведущий научный сотрудник лаборатории социального развития агропромышленного комплекса и сельских территорий, Институт аграрных проблем РАН, ул. Московская, 94, 410012 г. Саратов, Российская Федерация, iagpran@mail.ru, https://orcid.org/0000-0001-5104-2153 